\title{
Assessing the knowledge of trainee residents for liver involvement and related issues in COVID-19 pandemic
}

\author{
Muhammad Ali Qadeer ${ }^{1}$, Zaigham Abbas ${ }^{2}$, Muhammad Asim ${ }^{3}$, Shoukat Ali ${ }^{4}$, Abeer Altaf ${ }^{5}$ \\ 1,3,4,5 Fellow, ${ }^{2}$ Professor and Head, Department of Gastroenterology and Hepatology, Dr. Ziauddin University Hospital, \\ Clifton, Karachi, Pakistan
}

Background: Regular educational activities have suffered since the start of COVID-19 pandemic. New data has been emerging regularly regarding COVID-19 and the optimal way of care for patients with COVID-19 infection. Emphasis upon dispensing knowledge in current pandemic times should be made. Aims and Objective: We assessed the knowledge of internal medicine and gastroenterology trainees regarding liver involvement and related issues in the current COVID-19 pandemic. Materials and Methods: This online survey comprised of 10 questions designed to examine the basic knowledge of Sars-Cov-2 virus, knowledge regarding liver involvement in COVID-19, and the ability to decide on patient care. Results: A total of 100 responses were collected. Most of the responses were from Pakistan $(n=75)$. More than $80 \%$ of trainees responded correctly regarding the accurate indication of endoscopic procedures during COVID-19 pandemic, absence of ACE-II receptor expression on astrocytes, upper respiratory secretions being an eligible sample for SARSCOV-II, avoiding regular outpatient follow up, avoiding hydroxychloroquine as a prophylactic drug, and azithromycin in decompensated cirrhosis, continuing beta-blockers and lactulose in a decompensated patient, melena being an accurate indication for screening endoscopy and the choosing right set of PPEs. Less than $50 \%$ of responders knew correctly regarding NAFLD being a notorious factor for COVID-19 related complications, ACE-II receptor expression by cholangiocytes and enterocytes, saliva and stool being an eligible sample for SARS-COV-II detection, palliative approach as an appropriated management step for decompensated-CLD patients and history of ascites as an appropriate indication for screening endoscopy. GI trainees performed better in some areas of knowledge Conclusions: Trainees were updated in many aspects of the recent guidance in the management of COVID-19 but there were many lacunae in the knowledge. So, continuous medical education activities are essential to keep the residents updated about the changing developments in the management of COVID-19.

Key words: Knowledge; COVID-19; Liver; Gastroenterology; Internal Medicine; Trainees; Residents

\section{Access this article online}

Website:

http://nepjol.info/index.php/AJMS DOI: 10.3126/ajms.v12i5.33148

E-ISSN: 2091-0576

P-ISSN: 2467-9100

Copyright (c) 2021 Asian Journal of Medical Sciences

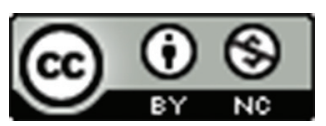

This work is licensed under a Creative Commons Attribution-NonCommercial 4.0 International License.

\section{INTRODUCTION}

In the late December 2019 cluster of pneumonia cases emerged in Wuhan, China. Later severe acute respiratory syndrome coronavirus 2 (Sars-Cov-2) was identified as the causative agent. ${ }^{1}$ In mid-January cases started pouring in from outside China ${ }^{2}$. Later, on 11th March, it was labeled as pandemic., ${ }^{2,3}$ Sars-Cov-2 has a median incubation period of 5.2 days ranging between 1 to 14 days. ${ }^{1,4}$ It is believed that patient zero had a zoonotic transmission but now the primary mode of transmission is from person to person. ${ }^{5}$ Symptoms through the course of illness include but not limited to fever (98\%), cough $(76 \%)$, dyspnea (55\%), myalgia or fatigue (44\%), sputum production $(28 \%)$, headache $(8 \%)$, hemoptysis $(5 \%)$, and diarrhea $(3 \%){ }^{6}$ The majority of the patients $(71 \%)$ 
have radiological involvement of lungs as evident on CT chest. $^{7}$

Since the emergence of coronavirus disease-19 (COVID-19), data regarding multi-organ involvement is being reported. ${ }^{8,9}$ This is attributed to the ubiquitous distribution of ACE-II receptors which serve as an entry point for the virus. ${ }^{10}$ Liver involvement as evident by deranged liver biochemistry has been reported ranging from $14 \%$ to $53 \%$ in hospitalized patients. ${ }^{1,11}$ Several mechanisms of liver injury have been postulated including immune-mediated damage, direct viral cytotoxicity, hypoxia, and drug-induced liver injury (DILI). ${ }^{12}$ Whether patients with chronic liver disease are more prone to develop decompensation or acute on chronic liver failure still needs to be answered. However, patients of chronic liver disease and liver transplant are already immune-compromised which make them more vulnerable to infections. ${ }^{13}$

It is important to maintain optimal standards of care for patients already suffering from liver diseases and prioritize the care of these patients in the current era of the COVID-19 pandemic. This survey focuses on assessing the knowledge of internal medicine residents and gastroenterology fellows (trainees) regarding liver involvement and related issues in the current pandemic situation.

\section{MATERIALS AND METHODS}

The survey comprises of 10 questions designed to examine (1) respondent demographics (2) basic knowledge of SarsCov-2 virus (3) knowledge regarding liver involvement in COVID-19 and (4) ability to decide on patient care. The questionnaire comprised of open-label questions, best choice questions, and questions with multiple correct answers. Residents of gastroenterology and hepatology (GI)and residents of internal medicine (IM)from multiple institutions and different countries were invited to participate in the survey. An introductory letter and HTML link to the survey was sent either via email or SMS. Reminder message was sent after 2 weeks to ensure good participation. The survey was also distributed among residents via different social media platforms (Facebook, Twitter, WhatsApp, and Instagram) to increase study participation. The survey was created on SurveyMonkey, an online survey development cloud-based software (SurveyMonkey, San Mateo, CA 94403). The free version of SurveyMonkey allows ten questions and up to 100 participants. Fisher exact test was used to find any associations between two categorical variables. A p-value of less than 0.05 was taken as significant for the nonrandom association. The ethics committee of the hospital approved the protocol.

\section{RESULTS}

\section{Demographic data}

A total of 100 responses were collected, 50 from each specialty (internal medicine (IM) and gastroenterology hepatology (GI). Most of the responses where from Pakistan $(\mathrm{n}=75)$ whereas 8 responses were from the USA, 7 from the UK, 2 from Canada, 2 from Italy, 2 from India, and one from Poland, Spain, Ireland, and Romania each. Fifty eight percent of the respondents were male and $42 \%$ were female.

\section{Question 1}

In response to the question regarding the indications of endoscopic intervention during the current COVID-19 pandemic, $87 \%$ of total respondents agreed that acute GI bleed would require endoscopic intervention. Out of a total of 87 respondents, 47 were from gastroenterology specialty whereas 40 were from internal medicine. Eightythree respondents (44 from GI and 39 from IM) agreed that surveillance endoscopic procedure could be avoided. 94\% of respondents (47 from each specialty) answered that endoscopic intervention would be required to achieve access for urgent feeding. 80\% (43 form GI and 37 from IM) agreed that diagnostic endoscopic procedures could be avoided in the current situation whereas only 55\% (34 from GI and 21 from IM) ( $=0.002)$ believed that diagnostic endoscopic ultrasound (EUS) should also be avoided. According to $88 \%$ of respondents (47 from GI and 41 from IM), biliary sepsis would require urgent endoscopic intervention.

\section{Question 2}

This MCQ question with the best choice answer enquired about the etiology underlying chronic liver disease that would make a patient most vulnerable to COVID-19 related complications. Only $17 \%$ of the respondents (13 from GI and 4 from medicine, $\mathrm{p}=0.031$ ) answered correctly by selecting non-alcoholic fatty liver disease (NAFLD) as the primary etiology. 45\% (24 from GI and 21 from IM) of the respondents selected cirrhosis by HBV or HCV as an etiology that would make a patient most vulnerable to COVID-19. 36\% (13 from GI and 23 from IM) answered HCC and only $2 \%$ (0\% from GI and $2 \%$ from medicine) answered HCV without cirrhosis as an etiology that would make a patient most prone to COVID related complication (Table 1a).

\section{Question 3}

This question focused on assessing the knowledge of the residents regarding ACE-II receptor expression on different cells of the body. Fifty three percent ( 25 from GI and 28 from IM) of total respondents answered correctly by saying that ACE-II receptors are not abundantly expressed 
on hepatocytes. Only 21\% (14 from GI and 7 from IM) of respondents answered right regarding the abundant expression of ACE-II receptors on cholangiocytes. Ninety eight percent (48 from GI and 50 from medicine) of respondents were sure enough that ACE-II receptors are not expressed by astrocytes. 74\% (39 from GI and 35 from IM) of respondents answered correctly by saying that ACE-II receptors are abundantly expressed by alveolocytes whereas only $28 \%$ (17 from GI and 11 from medicine) knew that ACE-II were also expressed abundantly by enterocytes (Table 1 a).

\section{Question 4}

In this question, knowledge of residents regarding samples eligibility for detecting SARS-COV-2 by running RTPCR was assessed. Options included saliva, respiratory secretions, blood, stool, and urine. 88\% (47 from GI and 41 from IM) answered correctly by selecting respiratory secretions as the eligible sample for detecting SARS-COV-2 on RT-PCR.44\% (18 from GI and 26 from IM) answered correctly by selecting saliva as another eligible sample for running RT-PCR. Sample of blood is not viable for running RT-PCR; 73\% (36 from GI and 37 from IM) of respondents answered this correctly. Only 38\% (23 from GI and 15 from IM) of respondents knew that SARS-COV-2 may also be detected in stool samples whereas the majority of the respondent $92 \%$ (47 from GI and 45 from IM) knew that urine is not a viable sample for running RT-PCR to detect SARS-COV-2.

\section{Question 5}

This question aimed to assess the knowledge of residents about the management of patients who have undergone a liver transplant. The majority of the residents $92 \%$ (44from GI and 48 from IM) correctly answered that such patients should avoid regular OPD follow-ups as this may expose them to infection. Seventy percent (32 from GI and 38 from IM) of respondents agreed on advising these patients to wear gloves and masks when at a public place. $98 \%$ (50 from GI and 48 from medicine) correctly answered by advising not to start hydroxychloroquine as prophylaxis for COVID-19. Ninety two percent (49 from GI and 43 from medicine) were correctly in favor of advising such patients to observe strict social distancing. 19\% (13 from GI and 6 from medicine) incorrectly advised stopping mycophenolate if being given as a second drug with tacrolimus (Table 1b).

\section{Question 6}

In this question knowledge of residents is being assessed about surveillance of esophageal varices and associated management. Seventy percent (36 from GI and 34 from IM) of total respondents agreed on postponing the procedure whereas 30\% (14 from GI and 16 from IM) were in the favor of getting endoscopy as per schedule. Sixty four percent ( 40 from GI and 24 from IM, $p=0.002$ ) of the respondents answered correctly in regards to the continuation of beta-blockers. $96 \%$ of total respondents agreed on continuing diuretics if already being given whereas $99 \%$ of the respondents selected not to stop lactulose (Table 1b).

\section{Question 7}

This question assesses the approach of residents in managing COVID-19 complications in a decompensated CLD patient. 60\% (32 from GI and 28 from IM) responded that they would not intubate such patients in-case they develop respiratory distress. On the other hand, only 44\% (32 from GI and 12 from IM, $\mathrm{p}=<0.001$ ) chose a palliative approach for such patients. 93\% (46 from GI and 47 from IM) opted not to do a CPR on a decompensated CLD patient. 85\% (44 from medicine and 41 from GI) respondents agreed on counseling the patient's family regarding poor prognosis if they develop COVID-19

\begin{tabular}{l} 
Table 1a: Comparison of core knowledge between $\mathbf{G l}$ and Internal Medicine \\
Questions \\
\cline { 2 - 3 }
\end{tabular}


Table 1b: Comparison of attitude between GI and Internal Medicine

\begin{tabular}{|c|c|c|c|c|}
\hline \multirow[t]{2}{*}{ Questions } & \multicolumn{2}{|c|}{ Correct answers given } & \multirow[t]{2}{*}{ Correct answers } & \multirow[t]{2}{*}{ P-value } \\
\hline & GI (n) & I-Medicine (n) & & \\
\hline \multicolumn{5}{|c|}{ In the current situation what advice you would give to a patient after a liver transplant? } \\
\hline Frequent OPD follow-ups for a regular check-up & 44 & 48 & Yes & 0.269 \\
\hline $\begin{array}{l}\text { Wear mask and gloves when shopping at a } \\
\text { departmental store }\end{array}$ & 32 & 38 & Yes & 0.275 \\
\hline Start prophylactic hydroxychloroquine & 50 & 48 & No & 0.495 \\
\hline Observe strict social distancing & 49 & 43 & Yes & 0.059 \\
\hline $\begin{array}{l}\text { Stop Mycophenolate if being given as a second } \\
\text { drug with tacrolimus }\end{array}$ & 37 & 44 & No & 0.125 \\
\hline \multicolumn{5}{|c|}{$\begin{array}{l}\text { In current COVID-19 pandemic a cirrhotic patient with past history of ascites and bleeding varices contacts you for surveillance endoscopy, } \\
\text { what advice would you give? }\end{array}$} \\
\hline Postpone the procedure & 36 & 34 & Yes & 0.828 \\
\hline Get endoscopy as scheduled & 36 & 34 & No & 0.828 \\
\hline Continue beta-blockers & 40 & 24 & Yes & $0.002^{*}$ \\
\hline Stop diuretics & 49 & 47 & No & 0.617 \\
\hline $\begin{array}{l}\text { Stop lactulose as it may alter gut flora and } \\
\text { promote SARS-COV-2 cell entry }\end{array}$ & 50 & 49 & No & 1.000 \\
\hline \multicolumn{5}{|c|}{ In current COVID-19 pandemic, to which of the following patients you would advised screening endoscopy? } \\
\hline Patients with history of melena. & 48 & 44 & Yes & 0.269 \\
\hline Patient with ascities & 13 & 6 & Yes & 0.125 \\
\hline Patient with thrombocyte counts of $140,000 / u l$ & 47 & 47 & No & 1.000 \\
\hline Patient with serum albumin of $2.9 \mathrm{~g} / \mathrm{dl}$. & 50 & 46 & No & 0.242 \\
\hline
\end{tabular}

\section{Table 1c: Comparison regarding knowledge of intervention between GI and Internal Medicine}

\begin{tabular}{|c|c|c|c|c|}
\hline \multirow[t]{2}{*}{ Questions } & \multicolumn{2}{|c|}{ Correct answers given } & \multirow[t]{2}{*}{ Correct answers } & \multirow[t]{2}{*}{ P-value } \\
\hline & GI (n) & I-Medicine (n) & & \\
\hline \multicolumn{5}{|c|}{ Which of the following indications does not require endoscopic intervention during the COVID-19 pandemic? } \\
\hline Acute GI bleeding & 47 & 40 & No & 0.071 \\
\hline Surveillance endoscopic procedures & 44 & 39 & Yes & 0.287 \\
\hline Access for urgent feeding & 47 & 47 & No & 1.000 \\
\hline Biliary sepsis & 47 & 41 & No & 0.121 \\
\hline Diagnostic EUS & 34 & 21 & Yes & $0.002^{*}$ \\
\hline Routine diagnostic endoscopic procedures & 43 & 37 & Yes & 0.211 \\
\hline \multicolumn{5}{|c|}{$\begin{array}{l}\text { A decompensated-CLD patient was hospitalized and was later found to have COVID-19. Now the patient is developing respiratory distress, } \\
\text { what steps would you take for its management? }\end{array}$} \\
\hline Intubate and ventilate & 32 & 28 & No & 0.541 \\
\hline Palliative care & 32 & 12 & Yes & $<0.001^{*}$ \\
\hline Perform CPR if the patient develops asystole & 46 & 47 & No & 1.000 \\
\hline Counsel the family regarding poor prognosis & 44 & 41 & Yes & 0.577 \\
\hline Start azithromycin & 39 & 44 & No & 0.287 \\
\hline \multicolumn{5}{|c|}{ Performing an endoscopic procedure on a patient with unknown COVID-19 status which of the following set of PPEs would you use? } \\
\hline Surgical mask, gloves, and goggles & 0 & 0 & No & 1.000 \\
\hline N95 mask, gloves, and goggles & 0 & 0 & No & 1.000 \\
\hline N95 mask, gloves, head-cap, face shield, shoe cover and gown & 2 & 3 & No & 1.000 \\
\hline Surgical mask, gloves, goggles, head-cover, face shield, shoe cover and gown & 0 & 2 & No & 0.495 \\
\hline N95 mask, gloves, goggles, head-cover, face shield, shoe cover and gown & 48 & 45 & Yes & 0.436 \\
\hline
\end{tabular}

related complications. Responding to starting azithromycin in such patients 83\% (39 from GI and 44 from IM) chose not to start it (Table 1c).

\section{Question 8}

This question enquires about the set of personal protection equipment (PPE) required to be worn in a patient undergoing an endoscopic procedure with unknown COVID-19 status. 93\% (48 from GI and 45 from IM) selected the right set of PPEs to be used i.e. N95 mask, gloves, goggles, head-cover, face shield, shoe cover, and gown (Table 1c).

\section{Question 9}

This question focused on assessing the knowledge of residents about correctly choosing patients who should be undergoing a screening endoscopy in the COVID-19 era. Ninety two percent (48 from GI and 44 from IM) of total respondents agreed on doing screening endoscopy on a patient with a history of melena. Whereas only $19 \%$ 
(13 from GI and 6 from IM) chose screening endoscopy for patients with a history of ascites. Ninety four percent (47 respondents each from GI and medicine) chose not to schedule screening endoscopy for patients on criteria of platelets count $<140,000 /$ ul. $96 \%$ (50 from GI and 46 from IM) answered in favor of not doing screening endoscopy on the criteria of low serum albumin $(<2.8 \mathrm{~g} / \mathrm{dl})$ (Table 1c).

We compared the knowledge of trainees in internal medicine with those in gastroenterology and could not find any significant differences between the two except knowledge regarding diagnostic EUS not being an indication of endoscopic procedure during COVID-19 pandemic, NAFLD making patients with the chronic liver disease most vulnerable to COVID-19 complication, continuing beta-blockers in all patients with a previously documented episode of decompensation and palliative care being an appropriate management step in the decompensated-CLD patient developing respiratory distress.

\section{DISCUSSION}

Coronavirus 2019 poses an equal risk to patients and healthcare providers thus it is of the utmost importance that all healthcare providers especially residents should not only have proper knowledge regarding this disease but should also know accurate indication when to refer or undertake a patient for a particular procedure. Several guidance has emerged for healthcare facilities to cope with the current situation. So, we administered this questionnaire related to COVID-19 to assess the knowledge of residents working in the field of IM and GI.

It has been observed that healthcare workers exposed to aerosolizing procedures have a high rate of acquiring SARS infection. ${ }^{14}$ Thus limiting such procedures will decrease exposure to SAR-COV-2. To limit endoscopic procedure, proper case by case evaluation should be performed and procedures that require emergent endoscopic intervention should be performed only. Upper gastrointestinal bleed, acute cholangitis, urgent feeding, foreign body obstruction, etc. are considered as emergent procedures by multiple international societies. ${ }^{15}$ In our study, we found that for most of the urgent endoscopic indications residents had adequate knowledge whereas only half of the respondents were aware of the fact that diagnostic EUS is not an indication for urgent intervention during current COVID-19 pandemic.

Metabolic syndrome is a leading cause of NAFLD and conditions such as diabetes or hypertension are linked with increased risk of COVD-19 related complications. ${ }^{16,17}$ In our study analysis, only $17 \%$ of the respondents were aware of this fact. Angiotensin-converting enzyme II (ACE-II) receptor is the functional receptor for SARS-COV-2 and understanding of its ubiquitous distribution explains the pathological involvement of different organs. ${ }^{10}$ Our study showed that respondents had sparse information regarding ACE-II receptor distribution. Almost half of the respondents were unaware that hepatocytes do not express ACE-II receptors abundantly and only $21 \%$ knew about the abundant expression of ACE-II receptors on cholangiocytes. Seventy two of the respondents were also not aware of the excessive expression of ACE-II receptors by enterocytes.

Real-time- PCR testing is yet considered the most reliable test for the detection of SARS-COV-II. Samples from different sites have different detection rates with bronchoalveolar lavage showing the highest detection rate followed by specimens of sputum, nasal swab. saliva etc. ${ }^{18,19}$ Our study showed that residents had adequate knowledge about the eligibility of respiratory secretions and non-eligibility of urine as a sample for the detection of SARS-COV-II by PCR testing. Only 44\% knew that saliva samples could also be used for detecting SARSCOV-II by PCR with the majority of respondents being from internal medicine. An equal number of respondents from both fields, in total $72 \%$ were aware of the fact that blood sample is not an eligible sample for detecting SARCOV-II. With the majority of the respondents from GI, in total $38 \%$ knew about the viability of stool as a sample for detecting SAR-COV-II.

Recent guidelines by EASL outlined some important recommendations for the management of patients of liver transplant in the current COVID era. ${ }^{16}$ The recommendations included abiding by social distancing, using personal protective equipment in crowded spaces, and minimizing hospital exposure. In our study respondents from both the field had adequate knowledge about these recommendations. As per recommendation by these guidelines $70 \%$ of respondents chose to postpone surveillance endoscopy.

Our study also showed that most of the respondents would counsel the family regarding the poor prognosis of decompensated cirrhotic patients with COVID-19 related complications whereas only a few $(44 \%$, majority from GI) chose a palliative approach for such patients. The majority of the residents were aware of the fact the azithromycin is not to be prescribed in decompensated cirrhotic patients and should also be avoided in decompensated CLD patients with COVID-19. ${ }^{20}$ 
The majority of the societies recommended using a proper set of PPEs during the endoscopic procedure including N95 mask, gloves, goggles/ face shield, head-cover, shoe cover, and gown. Our study showed that the majority of residents $(93 \%)$ from both specialties knew the set of PPEs to be used.

In recent literature, EASL advocated on using extended Baveno VI Criteria, history of variceal bleeding, and signs of portal hypertension for stratifying patients especially during COVID-19 pandemic and reserving screening endoscopy for only those patient that falls into a highrisk category. ${ }^{16}$ In our study, more than $90 \%$ of the respondents agreed to proceed for screening endoscopy in patients with a history of malena but only $19 \%$ chose to undertake a patient for screening endoscopy if the patient presents with a sign of decompensation (i.e. ascites).

We compared the knowledge of trainees in internal medicine with those in gastroenterology and could not find any significant differences between the two except in the knowledge directly related to their specialty. It is apparent that due to the continuous influx of new data related to COVID-19, frontline healthcare workers in all fields of medicine keep an eye on new developments equally. However, gastroenterology residents and trainees are expected to know more about the developments related to their specialty. The questionnaire was designed in a way to cover COVID-19 aspects unrelated to gastroenterology as well.

\section{CONCLUSION}

Trainees from IM and GI are updated in many aspects of the recent guidance in the management of COVID-19 but there are many lacunae in the knowledge. So, continuous medical education activities are essential to keep the residents updated about the changing developments in the management of COVID-19.

\section{REFERENCES}

1. Guan W, Ni Z, Hu Y, Liang W, Ou C, He J, et al. Clinical Characteristics of Coronavirus Disease 2019 in China. N Engl J Med. 2020;382(18):1708-1720.

https://doi.org/10.1056/NEJMoa2002032

2. Timeline of WHO's response to COVID-19 [Internet]. Who.int. 2020 [cited 30 August 2020]. Available from: https://www.who. int/news-room/detail/29-06-2020-covidtimeline

3. WHO Director-General's opening remarks at the media briefing on COVID-19 - 11 March 2020 [Internet]. Who.int. 2020 [cited 30 August 2020]. Available from: https://www.who.int/dg/speeches/ detail/who-director-general-s-opening-remarks-at-the-mediabriefing-on-covid-19---11-march-2020hj
4. Li Q, Guan X, Wu P, Wang X, Zhou L, Tong Y, et al. Early Transmission Dynamics in Wuhan, China, of Novel CoronavirusInfected Pneumonia. N Engl J Med. 2020;382(13):1199-1207. https://doi.org/10.1056/NEJMoa2001316.

5. Rothan HA and Byrareddy SN. The epidemiology and pathogenesis of coronavirus disease (COVID-19) outbreak. Journal of Autoimmunity. 2020; 109:102433. https://doi.org/10.1016/j.jaut.2020.102433

6. Jiang F, Deng L, Zhang L, Cai Y, Cheung CW and Xia Z. Review of the Clinical Characteristics of Coronavirus Disease 2019 (COVID-19). J Gen Intern Med. 2020;35(5):1545-1549. https://doi.org/10.1007/s11606-020-05762-w

7. Chung M, Bernheim A, Mei X, Zhang N, Huang M, Zeng X, et al. CT Imaging Features of 2019 Novel Coronavirus (2019-nCoV). Radiology. 2020;295(1):202-207. https://doi.org/10.1148/radiol.2020200230

8. Zaim S, Chong JH, Sankaranarayanan V and Harky A. COVID-19 and Multiorgan Response. Curr Probl Cardiol. 2020;45(8):100618. https://doi.org/10.1016/j.cpcardiol.2020.100618

9. Wang T, Du Z, Zhu F, Cao Z, An Y, Gao Y, et al. Comorbidities and multi-organ injuries in the treatment of COVID-19. The Lancet. 2020;395(10228): e52. https://doi.org/10.1016/S0140-6736(20)30558-4

10. Hamming I, Timens W, Bulthuis M, Lely A, Navis G and van Goor $\mathrm{H}$. Tissue distribution of ACE2 protein, the functional receptor for SARS coronavirus. A first step in understanding SARS pathogenesis. J Pathol. 2004;203(2):631-637. https://doi.org/10.1002/path.1570

11. Chen N, Zhou M, Dong X, Qu J, Gong F, Han Y, et al. Epidemiological and clinical characteristics of 99 cases of 2019 novel coronavirus pneumonia in Wuhan, China: a descriptive study. The Lancet. 2020;395(10223):507-513. https://doi.org/10.1016/S0140-6736(20)30211-7

12. Sun J, Aghemo A, Forner A and Valenti L. COVID-19 and liver disease. Liver Int. 2020;40(6):1278-1281. https://doi.org/10.1111/liv. 14470

13. Noor MT and Manoria P. Immune Dysfunction in Cirrhosis. J Clin Transl Hepatol. 2017;5(1):50-58. https://doi.org/10.14218/JCTH.2016.00056

14. Tran K, Cimon K, Severn M, Pessoa-Silva CL and Conly J. Aerosol Generating Procedures and Risk of Transmission of Acute Respiratory Infections to Healthcare Workers: A Systematic Review. PLoS ONE. 2012;7(4):e35797. https://doi.org/10.1371/journal.pone.0035797

15. Castro Filho EC, Castro R, Fernandes FF, Pereira G and Perazzo H. Gastrointestinal endoscopy during the COVID-19 pandemic: an updated review of guidelines and statements from international and national societies. Gastrointestinal Endoscopy. 2020;92(2):440-445.e6. https://doi.org/10.1016/j.gie.2020.03.3854

16. Boettler T, Newsome PN, Mondelli MU, Maticic M, Cordero E, Cornberg $\mathrm{M}$, et al. Care of patients with liver disease during the COVID-19 pandemic: EASL-ESCMID position paper. JHEP Reports. 2020;2(3):100113. https://doi.org/10.1016/j.jhepr.2020.100113

17. Huang C, Wang Y, Li X, Ren L, Zhao J, Hu Y, et al. Clinical features of patients infected with 2019 novel coronavirus in Wuhan, China. The Lancet. 2020;395(10223):497-506. https://doi.org/10.1016/S0140-6736(20)30183-5

18. Wang W, Xu Y, Gao R, Lu R, Han K, Wu G, et al. Detection of 
SARS-CoV-2 in Different Types of Clinical Specimens. JAMA. 2020 Mar 11

https://doi.org/10.1001/jama.2020.3786

19. Pasomsub $E$, Watcharananan $S$, Boonyawat $K$, Janchompoo $P$, Wongtabtim G, Suksuwan W, et al. Saliva sample as a non-invasive specimen for the diagnosis of coronavirus disease 2019: a cross- sectional study. Clinical Microbiology and Infection. 2020; May https://doi.org/10.1016/j.cmi.2020.05.001

20. Amarapurkar DN. Prescribing Medications in Patients with Decompensated Liver Cirrhosis. International Journal of Hepatology. 2011; 2011:1-5.

https://doi.org/10.4061/2011/519526

\section{Author's contribution: \\ All authors contributed equally.}

Work Attributed to:

Dr, Ziauddin University Hospital, Clifton, Karachi, Pakistan.

Orcid ID:

Dr. Muhammad Ali Qadeer - (i) https://orcid org/0000-0003-3811-9579

Prof. Dr. Zaigham Abbas - (1) https://orcid.org/0000-0002-9513-5324

Dr. Muhammad Asim - (i) https://orcid.org/0000-0002-3459-8907

Dr. Shoukat Al i- io https://orcid.org/0000-0003-2613-7294

Dr. Abeer Altaf - (1) https://orcid.org/0000-0002-0150-074X

Source of Funding: None, Conflict of Interest: None. 